\title{
Impact of the Granulation Process on Color Texture of Compacts
}

\author{
Berthe N'Dri-Stempfer*, Driss Oulahna*, Dominique Lafon**
}

\begin{abstract}
This paper examines the effect of the granulation process on the color texture of compacted powders and granules. The objective is to obtain information to provide for a better comprehension of granulation mechanisms by using a pigment as a texture marker.
\end{abstract}

This requires the establishment of a methodology both to qualify and quantify the spatial variation of color on the compact surface. This is achieved by color image analysis accompanied by both a statistical and a spatial treatment of the color content in the images.

Keywords: color image analysis, color texture compacts, compression, granulation, variance analysis

\section{Introduction}

The main purpose in engineering solid products as granules or compacts, is to impart user properties to powders including form, mechanical behavior and psycho-sensorial properties such as color.

One of the most widely used solid forming processes is compression $[1,2]$, which can be applied both to free powders without pre-treatment (direct compression) or to powders pre-conditioned by granulation. Granulation permits the fixing of the blend ingredients and improves the flow properties by enlargement of particle size [3]. These processes give a structure to the free powder, and consequently, have an effect on the texture and the color of compacts.

The color of compacted powders or granules results from the individual properties of the particles (size, shape, chemical composition and mineralogy), the collective properties of the particles (size and shape distributions) and the solid forming process (particle arrangement and surface states) [4]. In the past, color has been used as a tool to control solid-state stability in pharmaceutical

\footnotetext{
* B. N'Dri-Stempfer, D. Oulahna (corresponding author) LGPSD UMR CNRS 2392, Ecole des Mines d'Albi-Carmaux Campus Jarlard 81013 Albi France (driss.oulahna@mines-albi.fr)

** D.Lafon, Centre des Matériaux de Grande Diffusion, Ecole
} des Mines d'Alès, Hélioparc, 2 Av P.Angot, 64053 Pau-France processes [5]. Recently, some authors have used color as an indicator of the organization and the compactability of powder mixtures [6]. Our approach, developed in this paper, considers color as a marker of the solid forming process [7]. Solid forming by granulation can introduce color variations in granules and compacts. The spatial arrangement of the different colored regions is called color texture [7,8], and it is necessary to develop a means of characterizing this color texture.

The aim of this study is to propose a methodology to quantify the color texture of powders, granules and compacts, which combines colorimetry and color image analysis.

\section{Materials and Methods}

\subsection{Raw Materials}

The material used in this study is a mixture of $99 \%(\mathrm{w} / \mathrm{w})$ of a white powder $-75 \%(\mathrm{w} / \mathrm{w})$ of microcrystalline cellulose (Avicel $\left.{ }^{\circledR} \mathrm{PH} 105\right)$ and $25 \%$ (w/w) talc (Luzenac ${ }^{\circledR}$ Talc) - with $1 \%(\mathrm{w} / \mathrm{w})$ of a blue organic pigment phthalocyanin (Langdocyal ${ }^{\circledR}$ Bleu). The powder blend is obtained by successive dilutions [7] in a drum mixer, ERWEKA AR $402^{\circledR}$, at a speed of $15 \mathrm{rpm}$. This blend is called $\mathrm{C}_{75} \mathrm{~T}_{25} \mathrm{P}_{1}$ (Table 1). 
Table 1: Properties of the materials.

\begin{tabular}{lllccc}
\hline Material & $\begin{array}{l}\text { True density } \\
\left(\mathrm{g} / \mathrm{cm}^{3}\right)\end{array}$ & $\begin{array}{l}\text { B. E. T. specific } \\
\text { surface }\left(\mathrm{m}^{2} / \mathrm{g}\right)\end{array}$ & $\begin{array}{l}\text { Weight median } \\
\text { diameter } \mathrm{d}_{50}(\mu \mathrm{m})\end{array}$ & $\operatorname{Span}\left(\frac{d_{90}-d_{10}}{d_{50}}\right)$ & $\begin{array}{l}\text { Aerated bulk } \\
\text { density }\left(\mathrm{g} / \mathrm{cm}^{3}\right)\end{array}$ \\
\hline Micro-crystalline cellulose & 1.55 & 2.0 & 16 & 2.0 & 0.32 \\
Talc & 2.81 & 1.8 & 10 & 2.2 & 0.49 \\
Blue phthalocyanin & 1.71 & 59.4 & 3 & 2.3 & 0.33 \\
& & & & 1.9 & 0.35 \\
$\mathbf{C}_{\mathbf{7 5}} \mathbf{T}_{\mathbf{2 5}} \mathbf{P}_{\mathbf{1}}$ & 1.74 & 3.6 & 200 & 1.6 & 0.28 \\
Free powder & - & 1425 & 2.8 & 0.73 \\
Granules from fluidised bed & 3.83 & - & & \\
Granules from high shear mixer & 2.13 & & & & \\
\hline
\end{tabular}

\subsection{Granulation Process}

Granulation is performed using a $7.5 \%$ by weight solution in water of hydroxypropyl-methylcellulose (HPMC Pharmacoat $603^{\circledR}$ ) as a binder in two types of apparatus.

- Granulation in a Diosna $\mathrm{P} 1 / 6^{\circledR}$ high shear mixer with a 21 bowl. $200 \mathrm{~g}$ of powder is placed in the mixer bowl and the binder is dripped in, to give a binder content of $0.78 \mathrm{ml} / \mathrm{g}$ of powder.

- Granulation in a GEA Strea $1^{\circledR}$ fluidised bed granulator. $200 \mathrm{~g}$ of powder is put into the fluidised bed with air temperature of $50{ }^{\circ} \mathrm{C}$, and binder sprayed in at $0.35 \mathrm{~cm}^{3} / \mathrm{s}$, to give a binder content of $1.53 \mathrm{ml} / \mathrm{g}$ of powder.

\subsection{Compaction Process}

The powder or the granules are then compacted, using an Instron $5567{ }^{\circledR}$ instrumented laboratory press at a load of $25 \mathrm{kN}$. Compacts of $3 \mathrm{~cm}$ diameter $\left(7.1 \mathrm{~cm}^{2}\right)$ are formed during a compression cycle (Figure 1) at the speed of $10 \mathrm{~mm} / \mathrm{min}$, and the compact ejection speed is ca. $5 \mathrm{~mm} / \mathrm{min}$. The amount of material required to fill half the volume of the die $\left(18.7 \mathrm{~cm}^{3}\right)$, was calculated from the bulk density given in Table 1 .

\section{Colorimetric Approach}

\subsection{Color $[9,10]$}

The presence of color results from physical, physiological and psychological phenomena. It relates to the triplet "illuminant - object - observer" and results from the interactions between the material being observed and the magnetic radiation of the light. The sensation produced by this radiation on the eye is called color. Colorimetry is the quantification of the color of an object by attributing precise co-ordinates in a colorimetric space. Color spaces are 3-dimensional space where color

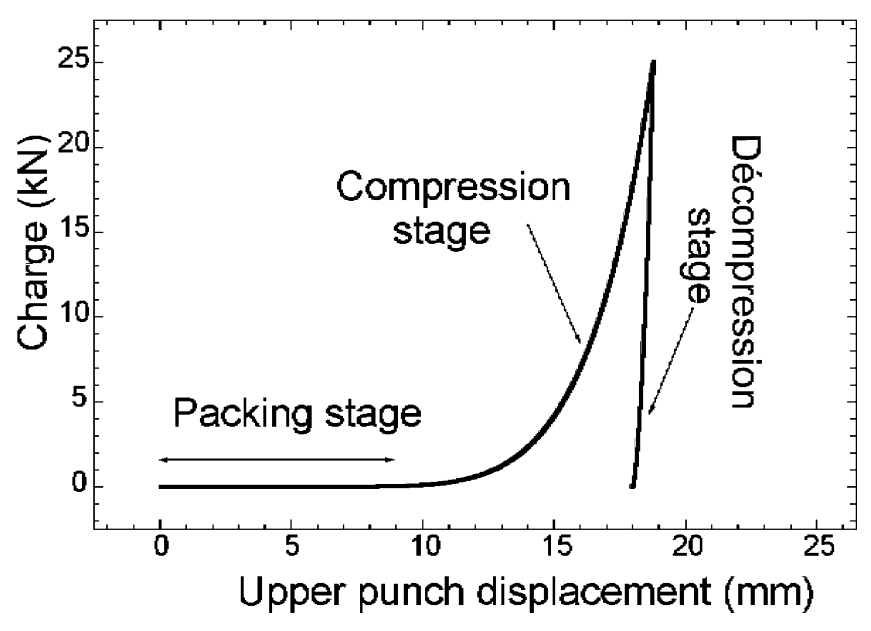

Fig. 1: Illustration of a compression cycle. Example of a $\mathrm{C}_{75} \mathrm{~T}_{25} \mathrm{P}_{1}$ powder.

is represented by vectors. These representations in color space take into account both the illuminant and the observer. There are many color spaces but it is possible to classify them into four families [11-13].

- Primary systems where the three vectors are primary colors. The first primary system created by the CIE (Commission Internationale de l'Eclairage) was the RGB (red-green-blue) system. There are other primary systems such as the XYZ and CMJ systems.

- Perceptual systems: L.a.b., L.u.v. or Munsell space. These are uniform color spaces in terms of visual perception. In these spaces, small color variations are numerically described, by the distance between two given points.

- Luminance-Chrominance systems where color is represented according to three intuitive directions. These systems permit the dissociation of luminance from chrominance.

- Independent-axis systems, which introduce mathematical transformations in order to de-correlate the colorimetric components. 
In this study, we have use the "L.a.b." space as color representation space [9].

\subsection{Color Texture Analysis}

Color texture analysis was carried out both on compacts composed of free powder and of granules. The objective is to reveal the influence of the solid forming process on the color texture of the compact.

The analysis of color texture is based on the acquisition of color images containing colorimetric information and consists of making a statistical analysis on the colorimetric values of the color image. This requires two steps: the acquisition of color images and the numerical treatment of these images [8].

\subsubsection{Acquisition}

Digital images were obtained using a 3CCD (Charge Coupled Device) camera, Sony ${ }^{\circledR}$ X003p. Acquisition was performed under constant diffuse lighting (identical spectral irradiance for all images). The observation distance was fixed and the image definition was about $50.8 \mu \mathrm{m} /$ pixel. Camera and frame grabber settings were fixed in order to obtain RGB coding without any signal enhancement.

Images were then converted from the RGB camera system to the "L.a.b." color space in two steps:

- Conversion of images in a device independent color space (CIE "XYZ" color space) [14] using parameters obtained via a colorimetric calibration process.

- Conversion to the "L.a.b." color space.

The "L.a.b." colorimetric co-ordinates are related to lighting conditions via the characterization of a "reference white" under real lighting conditions. The coordinates of this "reference white" are obtained by irradiance measurements using a spectroradiometer Spectrascan PR650 ${ }^{\circledR}$.

\subsubsection{Numerical Treatment}

The numerical treatment consists of studying the color of each pixel of the image. In this context, the $(\mathrm{L}, \mathrm{a}, \mathrm{b})$ triplet is calculated for each pixel, by conversion of initial $(R, V, B)$ device dependant coding.

First of all, a statistical analysis of $(L, a, b)$ values is performed in order to obtain information about the mean color of the surface and the scattering of pixel values around the mean. Following this, the spatial color pattern is studied by a texture analysis performed through a variographic approach [7]. The variogram is the representation of variance between two points, separated by a value $h$. This function expresses the probability that, two points $x$ and $x+h$ are different. If we consider a given line of an image divided into $\mathrm{n}$ pixels related to a triplet $\left(L_{i}, a_{i}, b_{i}\right)$, the variance function can be expressed as follows:

$S(h)=\frac{\sum_{j=1}^{n}\left(X_{i+h}-X_{i}\right)}{n} \quad$ where $\quad \mathrm{X} \in\{L, a, b\}$

$h$ : distance between pixels in a given direction.

The variograms of $L, a$ and $b$ give textural information in a given direction on the image $\left(0^{\circ}, 90^{\circ}, 45^{\circ}\right.$ and $\left.135^{\circ}\right)$ : $L$ is the luminance axis (white-black), $a$ is the red-green axis and $b$ is the yellow-blue axis. This analysis does not take into account the correlation between the three coordinates. In other words, color sensations cannot be expressed through a marginal approach where each coordinate is analyzed separately.

Spatial analysis can also be performed by a global approach that consists in determining average color differences with respect to the distance between pixels. This is the mean-difference-difference $C D_{\text {mean }}$ and in this analysis the observer does not distinguish between information on $L, a$ and $b$. The graphical representation of $C D_{\text {mean }}$ is similar to a variogram,

$$
\begin{aligned}
& C D_{\text {mean }}(h) \\
& \quad=\frac{\sum_{j=1}^{n} \sqrt{\left(a_{i+h}-a_{i}\right)^{2}+\left(b_{i+h}-b_{i}\right)^{2}+\left(L_{i+h}-L_{i}\right)^{2}}}{n} .
\end{aligned}
$$

A graphical representation of variance (variograms or $C D_{\text {mean }}$ ) gives information about the maximum variance calculated and a range, which is representative of a correlation distance between the points studied, (Figure 2).

\section{Results}

In order to increase the particle size the powder $\mathrm{C}_{75} \mathrm{~T}_{25} \mathrm{P}_{1}$ is subjected to two methods of binder granulation. Granulation by a high shear mixer results in denser (Table 1) and coarser granules (Figure 3). On the other hand, fluidized bed granulation gives intermediate size granules (Figure 3), with an aerated density close to that of the free powder (Table 1). Furthermore, granulation has an influence on the compression cycle via improvement of the flow properties of the powder and reduction of the packing stage in the compression process (Figure 4) [15]. 


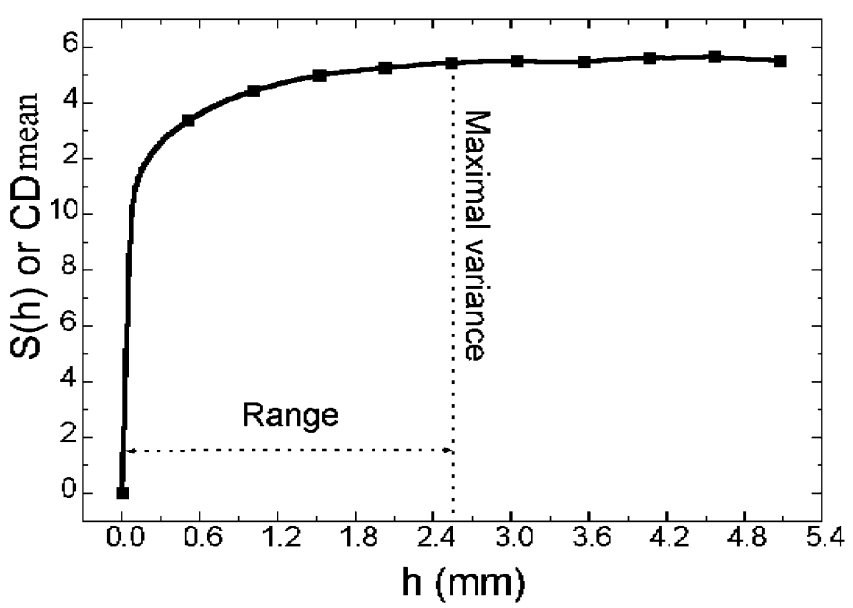

Fig. 2: Illustration of a variance graph.

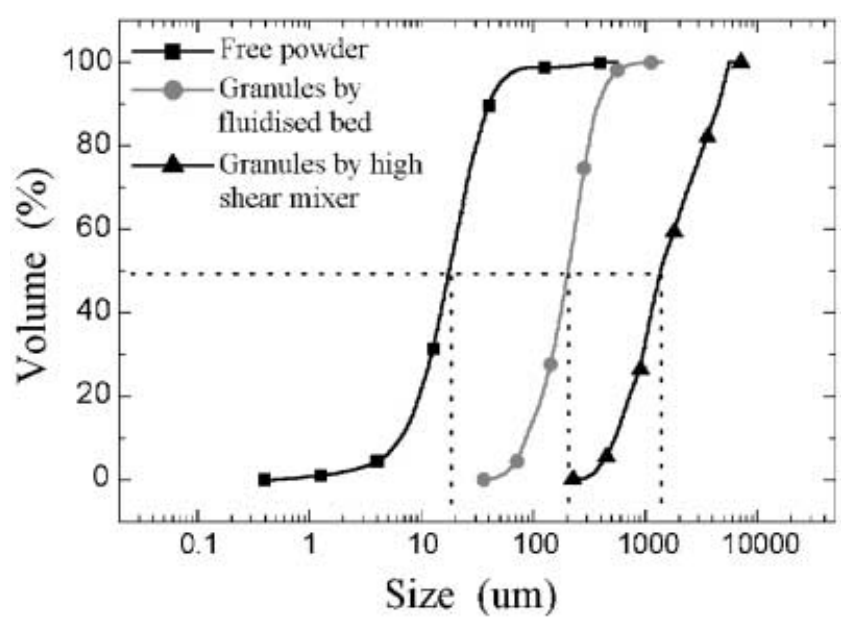

Fig. 3: Size distribution of $\mathrm{C}_{75} \mathrm{~T}_{25} \mathrm{P}_{1}$ powder particles and granules of $\mathrm{C}_{75} \mathrm{~T}_{25} \mathrm{P}_{1}$ from fluidised bed and high shear mixer.

In addition, granulation can improve the blend stability by creating micro-blends inside the granules. It has been seen previously that the granule texture differs according to the granulation process used. All of these factors, when taken into consideration, lead to different color textures related to the different granulation processes. The mechanisms of granulation are therefore responsible for a color texturation inside the granules and consequently, also inside the compact. In other words, it is important to estimate and quantify the process contribution, in order to control, and optimize the final visual aspect of compacts.

\subsection{Representation in the "Lab" Color Space}

In this section, the incidence of the granulation compression process is examined from a colorimetric point of

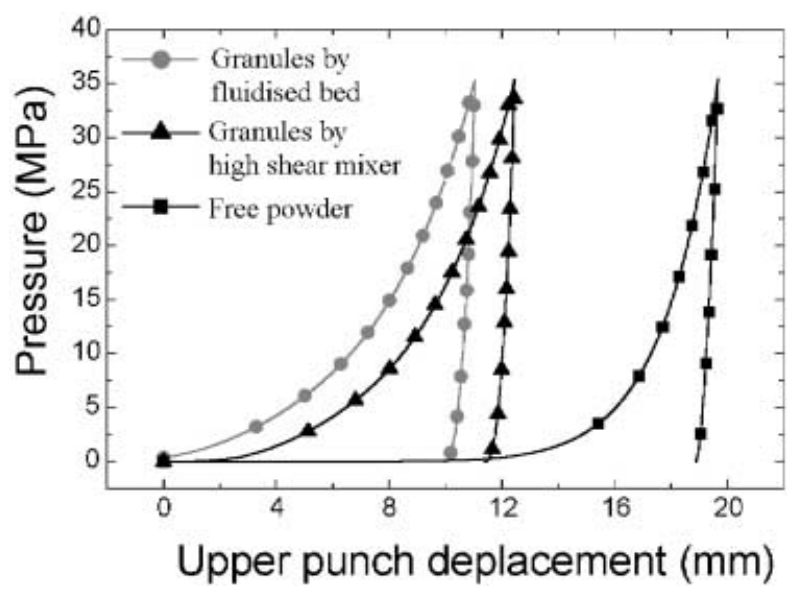

Fig. 4: Compression cycle of $\mathrm{C}_{75} \mathrm{~T}_{25} \mathrm{P}_{1}$ powder particles and granules of $\mathrm{C}_{75} \mathrm{~T}_{25} \mathrm{P}_{1}$ from fluidised bed and high shear mixer.

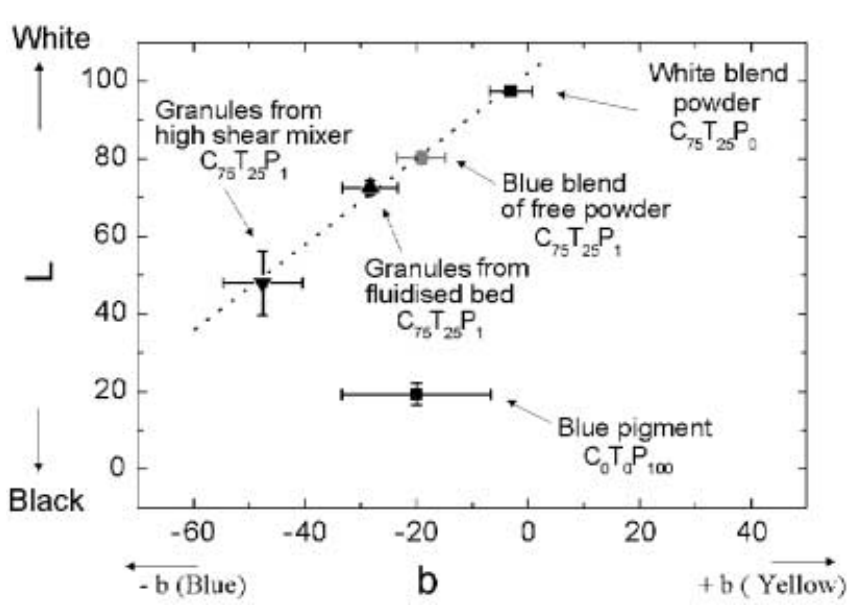

Fig. 5: Representation in (L, b) plane: lightness/blue-green.

view. The "Lab" color space is a 3-dimensional space and for clarity, 2D on projection planes are used. As the pigment used is blue, the information is carried by $(L, b)$ and $(a, b)$ planes (Figure 5 and Figure 6). On these projections, two reference co-ordinates are added: the blue pigment and the white powder blend $\mathrm{C}_{75} \mathrm{~T}_{25} \mathrm{P}_{0}$, which is composed of $75 \%(\mathrm{w} / \mathrm{w})$ microcrystalline cellulose and $25 \%(\mathrm{w} / \mathrm{w})$ talc.

\subsection{1 $(L, b)$ Plane}

The first observation is that, irrespective of the process used, the standard deviation is larger on the $b$-axis than on the $L$-axis, except in the case of granules from the high shear mixer. Hue dispersion is more important than lightness dispersion, except for granulation by the high shear mixer, where the process introduces lightness dispersion. 


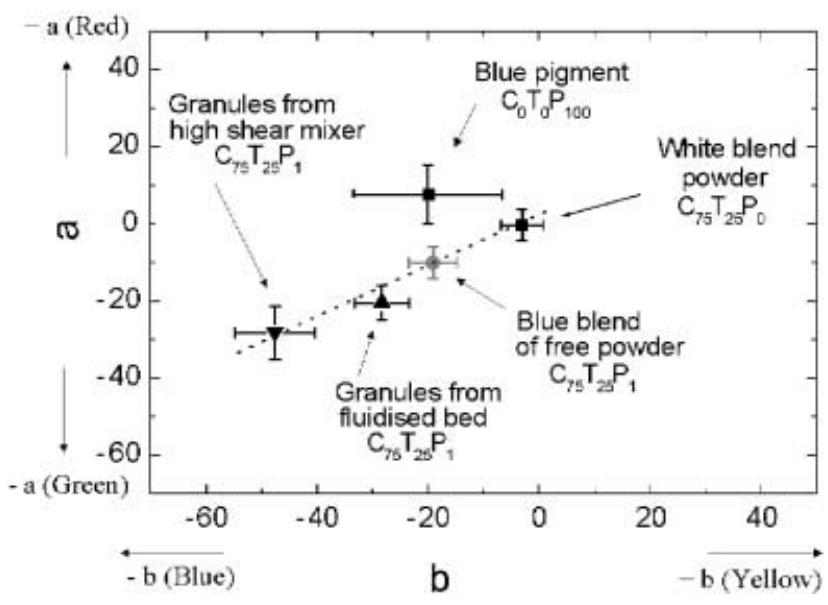

Fig. 6: Representation in $(a, b)$ plane: hue expression.

It is also noticeable that lightness decreases with granulation and that granules from the high shear mixer are the darkest. In addition, $b$-values decrease with granulation (negative values), which means that granules are bluer. In the case of the high shear mixer, it seems that the process improves the dispersion of the pigment and consequently increases its colorant power. Moreover, compacts are observed on the same straight line, which indicates dependence between the $L$ and $b$ co-ordinates. On the other hand, the pigment is perceived as black (low value of $L \rightarrow$ dark; low value of $b$ around $0 \rightarrow$ achromatic) in this projection. This may be explained by the fact that the pigment is very absorbent.

\subsection{2 $(a, b)$ Plane}

In this plane, compacts present a significant standard deviation both on the $a$ - and $b$-axis. This confirms the former observation that compacts present dispersion in terms of hue. Furthermore, compacts can be differentiated according to the process involved and their coordinates lie on a straight line. Thus, the co-ordinates $a$ and $b$ are linked together, as are the coordinates $L$ and $b$.

\subsection{Spatial Analysis of Color Texture (Variograms and $\left.C D_{\text {mean }}\right)$}

The analysis of the variance of one parameter ( $L, a, b$ or $\left.C D_{\text {mean }}\right)$ in terms of the incremental distance h, permits to study the color texture of an image. Figure 7 shows the results of the calculations of variance. Preliminary studies show that the process does not produce oriented texture as the variograms are the same at $0^{\circ}, 90^{\circ}, 45^{\circ}$ and $135^{\circ}$.
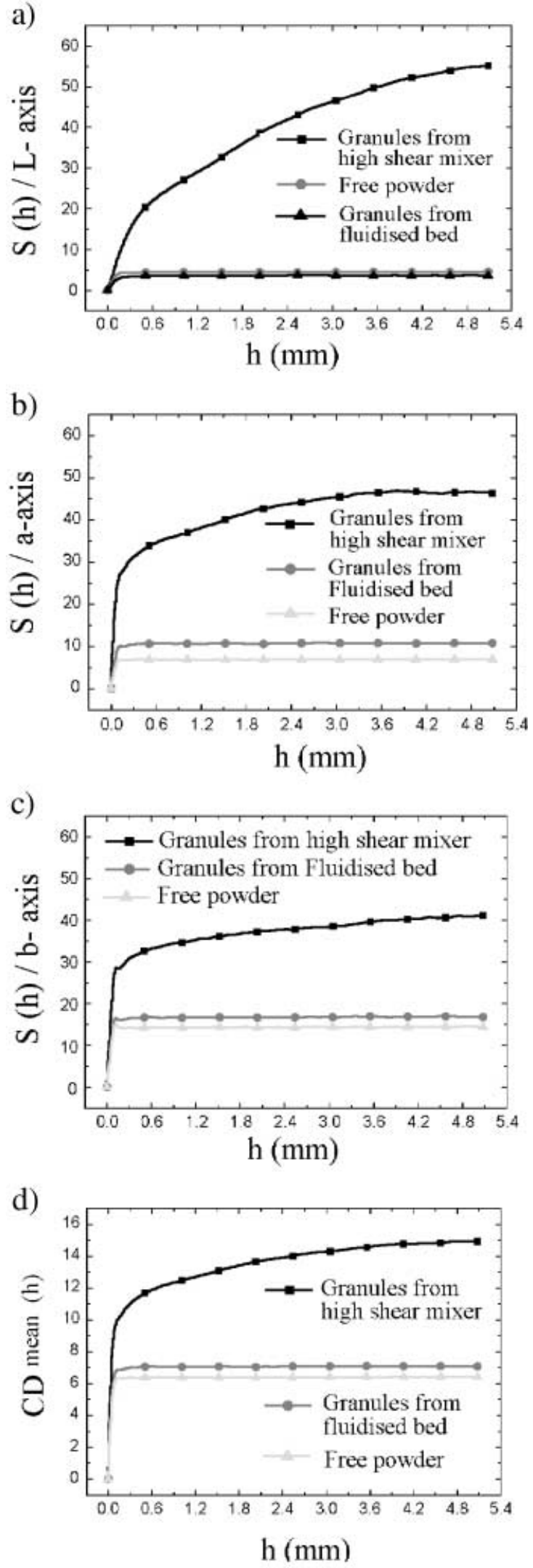

Fig. 7: Graphical representation of textural analysis: variograms of images of powder and granules compacts. Study of a) $L-$, b) $a$ and c) $b$-axis and d) $C D_{\text {mean }}$-axis. 


\subsubsection{Variance of $L$-axis}

The variance value gives information about the homogeneity of lightness at the surface of the compact. It can be seen (Figure $7(a)$ ), that granules from the high shear mixer are more heterogeneous $\left(S(h)_{\max }=60 / L\right.$-axis) than both the free powder and granules from the fluidized bed $\left(S(h)_{\max }=3 / L\right.$-axis).

The shape of the curve gives information on the texture. For the compact made from free powder, there is a correlation between the points of the curve over a distance of $200 \mu \mathrm{m}$. For greater distances, there is no correlation between the $L$-values of two pixels. In other words, at a scale less than $200 \mu \mathrm{m}$, the texture can be considered to be a random arrangement.

This correlation distance can be related to the size of pigment agglomerates present at the powder compact surface [7]. For granules from the fluidized bed, the texture of the compact is close to that of the free powder compact. The correlation distance of about $250 \mu \mathrm{m}$, is comparable with the granule size, and may be representative of a texture created by grain boundaries at the compact surface. Finally, for granules from the high shear mixer, the correlation distances are very high and in this case, there is no stabilization in the fields studied. This means that there is texturation at the compact surface for distances greater than $5.4 \mathrm{~mm}$. The visual illustration of this is a blue mosaic, with different lightness.

\subsubsection{Variance of the $a$-axis and the $b$-axis}

Variances give information about color texturation in terms of hue. The changes in the curves are the same on both the $a$-axis and the $b$-axis (Figure 7 (b) and Figure $7(\mathrm{c}))$. The variance of the free powder compact is the lowest, followed by the variance of the granules from the fluidized bed and finally, the granules from high shear mixer. Earlier remarks still remain valid: the compact made of granules from the high shear mixer are more heterogeneous in terms of hue than the other compacts. Moreover, on these two figures, a correlation distance of about $3 \mathrm{~mm}$ is observed, which is comparable with the granule size.

\subsubsection{Mean Color Difference ( $\left.C D_{\text {mean }}\right)$ as a Function of Distance}

The changes in the $C D_{\text {mean }}$, at progressively greater distances, yield wider information about color texture. It integrates information about the three axes, $L, a$ and $b$. The conclusion is still as before: The compact made of free powder has the lowest $C D_{\text {mean }}$, and followed by the compact composed of granules from fluidized bed (Figure $7(d))$. The two textures are very close, whereas the
Table 2: Principal characteristics of the $\mathrm{CD}_{\text {mean }}$ graph.

\begin{tabular}{lcl}
\hline Compacts of $\mathrm{C}_{75} \mathrm{~T}_{25} \mathrm{P}_{1}$ & $\begin{array}{l}\text { Maximal vaule } \\
\text { of } C D_{\text {mean }}\end{array}$ & Range $(\mathrm{mm})$ \\
\hline Free powder & 6 & 0.3 \\
Granules from fluidised bed & 7 & 0.4 \\
Granules from high shear mixer & 15 & 5.0 \\
\hline
\end{tabular}

compact of granules from the high shear mixer is very textured. Nevertheless, this calculation is very interesting because it gives a rapid estimation on the existence (or absence) of a color texture. But it does not permit the determination of the influence of each axis, $(L$-axis, $a$-axis and $b$-axis), on the perceived texturation.

It is observed that a value of color difference equal to 1 corresponds to a color difference just discernible by a standard observer [16]. In Table 2, we can see that the difference between the values of $C D_{\text {mean }}$ of the free powder and the granules from the fluidized bed, is equal to 1 , and is therefore, just perceptible. On the contrary, the differences with granules from the high shear mixer are ca. 8 or 9 , and are therefore, very perceptible.

\section{Conclusion}

Granulation is a pre-treatment process, which can improve the flow properties of powders. In addition agglomeration of particles by granulation, creates microblends in granules and can induce modifications in powder texture.

The methodology presented in this study proposes a spatial analysis of a color image in order to quantify the color texture obtained on a compact.

It is seen that the granulation process has an influence on the color texture of powder compacts. Granulation by a high shear mixer gives coarser and denser granules that are more saturated (bluer), and more textured. On the other hand, granulation in a fluidized bed gives intermediate sized granules with density, color and color texture very close to that of the free powder.

This powder formulation process introduces texturation of the product, and this new approach for color texture characterization can be use as a control tool for products.

\section{Nomenclature}

$\begin{array}{ll}C D_{\text {mean }} & \begin{array}{l}\text { mean Difference-Difference } \\ \text { distance between two pixels from a given }\end{array} \\ \text { image } \\ \text { L.a.b. space } & \text { color space } \\ S(h) & \text { variance function }\end{array}$




\section{References}

[1] G. Ragnasson, Force Displacement and Network Measurements in Pharmaceutical Powder Compaction Technology. in Drugs and the Pharmaceutical Sciences (Eds.: G. Alderborn, C. Nystrröm), Marcel, USA, 1996, 71, 77-97.

[2] J. C. Masteau, Compressibilité et Cohesion de Produits Pharmaceutiques. Etude et Modelisation du Comportement de Mélange Binaires, PhD Thesis, EMSE-INP Grenoble, France, 1998.

[3] N. G. Stanley-Wood, M. Rhodes, Size Enlargement in Principles of Powder Technology. Wiley, England, 1993, p. 193.

[4] H. Bozec-Garay, Paramètres Morphogranulométriques et Comportement Optique des Matériaux Divisés, PhD Thesis, EMSE-INP Grenoble, France, 2000.

[5] D. G. Pope, J. L. Lach, Some Aspects of Solid State Stability and Diffuse Reflectance Spectroscopy. Pharm. Acta Helv. 1975, 50, 165-177.

[6] J. Barra, A. Ullrich, F. Falson-Rieg, E. Doelker, La Couleur comme Indicateur de l'Organisation et de la Compactibilité des Mélanges Binaires Pulvérulents. Pharm. Dev. Technol. 2000, 5, 87-94.

[7] B. N'Dri-Stempfer, Etude de l'Incidence des Procédés de Granulation et de Compression sur la Couleur des Compacts de Poudres et de Granules, PhD Thesis, EMSE-INP Grenoble, France, 2001.
[8] Y. Bourada, D. Lafon, O. Eterradossi, Characterization of Color Texture. Color texture Based Sorting of Tiles. EUROPTO Conference on Electronic Imaging: Processing, Printing and Publishing in Color, Zurich, Switzerland, 1998.

[9] P. Kowalinski, Vision et mesure de la couleur, in Vision et Mesure de la Couleur ( $2^{\text {nd }}$ Eds.: F. Vienot, R. Seve), Masson, France, 1990.

[10] D. B. Judd, G. Wyszecki, Physics and Psychophysics of Colorant Layers, in Color in Business, Sciences and Industry, Wiley, USA, 1975, p. 397.

[11] K. Knoblauch, F. Vienot, Revue de «Physique de la Couleur: de l'Apparence Colorée à la Technique Colorimétrique». Color Research and Application, 1998, 23, 189-190.

[12] M. D'Zmura, P. Colantoni, J. Hagedorn, Perception of Color Change. Color Research and Application, 2001, 26, 186-191.

[13] K. Knoblauch, Spring School on Colorimetry and Colour Images, GdR ISIS, Pau, France, 2001.

[14] P. Laflaquière, D. Lafon, O. Eterradossi, P. Slangen, EUROPTO Conference on Electronic Imaging: Processing, Printing and Publishing in Color, Zurich, Switzerland, 1998.

[15] B. N'Dri-Stempfer, D. Oulahna, O. Eterradossi, A. Benhassaine, J. A. Dodds, Binder Granulation and Compaction of Coloured Powders. Powder. Technol. 2003, 130, 247-252.

[16] AFNOR, in Dictionnaire de Colorimetrie Théorique et Technique, $3^{\mathrm{ème}}$ édition, AFNOR, France, 1989. 